\title{
Cerebral palsy: effects of twinning, birthweight, and gestational age
}

\author{
Katrina Williams, Enid Hennessy, Eva Alberman
}

\begin{abstract}
Aims-To determine the effects of birthweight and gestational age on the risk of cerebral palsy for multiple and singleton births.

Methods-Children on the North East Thames Regional Health Authority Interactive Child Health System, born between 1 January 1980 and 31 December 1986, and notified as having cerebral palsy, were included. Cases of postneonatal onset, of known progressive, or non-cerebral pathology and with only mild signs were excluded. Rates and relative risks were calculated using the most complete data, which related to $1985-86$, and comprised 102059 singletons and 2367 twins. Logistic regression was used to examine the associations between being a twin, gestational age, and birthweight.

Results-The crude rate per 1000 survivors at 1 year of age was 1.0 in singletons and 7.4 in twins. The relative risk was greatest in twins weighing more than 2499 g (4.5). However, after adjusting for reduced birthweight of twins it was the relative risk of twins weighing less than $1400 \mathrm{~g}$ that was significantly increased. Logistic regression confirmed that lower fetal growth, lower gestational age, and being a twin are all independent risk factors for cerebral palsy.

Conclusion-The increased risk to twins of cerebral palsy is not entirely explained by their increased risk of prematurity and low birthweight.

(Arch Dis Child 1996;75:F178-F182)
\end{abstract}

Department of Epidemiology and Medical Statistics, St Bartholomew's \& Royal London School of Medicine, London Katrina Williams Enid Hennessy

The Wolfson Institute of Preventive Medicine, St Bartholomew's \& Royal London School of Medicine Eva Alberman

Correspondence to: Dr Katrina Williams, Department of Paediatrics and Child Health, The New Children's Hospital, PO Box 3515, Parramatta NSW 2124, Australia.
Keywords: cerebral palsy, twins, singletons, birthweight, gestational age.

The increased risk of both mortality and cerebral palsy in multiple births ${ }^{1-3}$ has been known for many years. However, good population based estimates of the risks of cerebral palsy relative to singletons have been available only recently. ${ }^{4-5}$ These associations are of interest firstly because rates of multiple births are increasing, in part due to the introduction of treatments for infertility. ${ }^{6-7}$ Secondly, differences between the pattern of cerebral palsy in twins and singletons generate aetiological hypotheses.

A register of children notified as having cerebral palsy was set up in the North East Thames Regional Health Authority. Linkage of these data with the records of those children on the Regional Child Health Computer System (RICHS) permitted the calculation of popula- tion based risks for twins and singletons in this region. ${ }^{8}$ This system includes data on gestational age that are not available from birth registrations. It made possible comparisons not previously reported: estimation of relative risks for gestational age, weight for gestational age, and birth weight categories adjusted for the different "normal" distribution of twins and singletons; and the use of the method of logistic regression to adjust for associations between these variables.

\section{Method}

The register was set up in 1985 with the aim of ascertaining affected children born since 1980 . Multiple sources of ascertainment were used, including general practitioners, paediatricians, orthopaedic surgeons, and SCOPE (formerly the Spastics Society). The Office of Population Censuses and Surveys (OPCS) were asked for names of eligible children who were certified as having died with cerebral palsy. As a deliberate policy, no definition of cerebral palsy was given to notifiers and no inclusion or exclusion criteria were specified.

The paediatrician responsible for the management of each notified case was asked for a detailed assessment, and to obtain parental consent for release of medical information to the register at the child's next visit. Over 30 paediatricians and their staff contributed information to the study. Further information about each child was sought when they were between 3.5 and 4 years and again between 7 and 8 years, although this was not always forthcoming. Clinical information about the distribution, type, and severity of cerebral palsy was available for $85 \%$ of cases born in 1985 and 1986. DENOMINATOR DATA AND MATCHING

In 1985 and 1986 RICHS data quality was validated by comparison with regional birth registration data, after excluding obvious duplicates (children born within the region but outside their district of residence or those who had moved within the region). For children about whom information on birthweight, number of children in the pregnancy, and outcome of birth was available, the two data sets were very similar, including the distribution of children of different birthweight groups for both twin and singleton births (table 1).

Matching children on the cerebral palsy register with their RICHS records permitted the validation of birth and residence data reported for the cerebral palsy cases. Matching was attempted for all cases notified to the register, but its success was limited for 1980 through 
Table 1 Number of live births and survivors at one year in NETRHA in 1985 and 1986 from RICHS and OPCS data

\begin{tabular}{llllllll}
\hline \multicolumn{7}{c}{ Birthweight } \\
\cline { 3 - 7 } & & $<1000 \mathrm{~g}$ & $1000-1499 \mathrm{~g}$ & $1500-2499 \mathrm{~g}$ & $\geq 2500 \mathrm{~g}$ & Not known \\
\hline Singleton: & & & & & & \\
$\quad$ Live births & RICHS & 252 & 531 & 5286 & 94245 & 1745 & 102059 \\
Survivors & OPCS & 256 & 545 & 5494 & 96322 & 124 & 102741 \\
& RICHS & 119 & 458 & 5127 & 93832 & 1735 & 101271 \\
Twins: & OPCS & 119 & 470 & 5323 & 95863 & 105 & 101880 \\
Live births & RICHS & 63 & 116 & 999 & 1103 & 86 & 2367 \\
Survivors $\star$ & OPCS & 58 & 107 & 964 & 1070 & 7 & 2206 \\
& RICHS & 29 & 98 & 983 & 1095 & 84 & 2289 \\
\hline & OPCS & 26 & 91 & 942 & 1060 & 6 & 2125 \\
\hline
\end{tabular}

* Survivors at one year.

1984 because RICHS data were not available for the whole region.

The matching process was in three stages. First, the birth date, the first four letters of first names and gender were matched with the RICHS system data, which did not include surnames. If cases from the register matched for these parameters they were then matched for birthweight (stage 2). If birthweights did not match or were absent, further matching was undertaken (stage 3 ) by seeking written information about the first four letters of surnames from district RICHS managers. For a registered case to be regarded as matched with RICHS data, the date of birth, first four letters of first name and gender, and either the birthweight, to within $30 \mathrm{~g}$, or the first four letters of their surname, had to be the same.

Children were excluded if the cause of their motor signs was known to be progressive or not cerebral in origin, the cause of their cerebral palsy was a postneonatal event, or no limb had an involvement greater than 1 on the severity coding system. ${ }^{9}$ Children who were not matched on the RICHS data, or where matched RICHS data did not include outcome of birth or number of children born, were also excluded. Cases were allocated to twin or singleton categories on the basis of RICHS data, regardless of information given to the register. The register included no triplet or higher order multiple births born in 1985-86.

\section{ANALYSIS}

Analysis was largely restricted to 1985 and 1986 , the two years over which both data sets were of good quality. Crude birthweight specific rates of cerebral palsy were determined for survivors at 1 year and crude gestational age specific rates for maternities bearing at least one live child still surviving at 1 year. To allow for the effect of infant death when comparing twin and singleton births, a "death or cerebral palsy" rate has also been calculated.

Birthweight analysis was done in two ways. Firstly, traditional categories were used to allow comparison with other studies. Secondly, adjusted birthweight categories were created to allow "equivalent" comparison of twins and singletons. This was done by subtracting, from traditional birthweight category boundaries, the difference in mean birthweight between twins and singletons of the same gestational age, using standards reported from Scotland. ${ }^{10}$
Thus where the mean birthweight of singletons was close to $2500 \mathrm{~g}$ (at 35 weeks of gestation), the mean birthweight of twins of the same gestational age was about $300 \mathrm{~g}$ less, so that the corresponding boundary for twins became $2200 \mathrm{~g}$. Similarly, where the mean weight of singletons was close to $1500 \mathrm{~g}$ (30 weeks), the mean of twins was about $100 \mathrm{~g}$ less, making the boundary $1400 \mathrm{~g}$. The difference of $100 \mathrm{~g}$ was also found where the mean weight of singletons was about $1000 \mathrm{~g}$ (26 weeks), making the corresponding boundary for twins $900 \mathrm{~g}$.

Multiple logistic regression analysis was used to explore the relative importance of risk factors for cerebral palsy; twin vs singleton birth, gestational age and fetal growth (the difference in birthweight from mean birthweight for a given gestation, specific for twins and singletons). Low fetal growth was also regarded as a dichotomous variable and defined as all cases with fetal growth of less than 1.5 standard deviations below the mean fetal growth (about $675 \mathrm{~g}$ below the mean and $5.6 \%$ of babies). For this analysis only survivors at 1 year born between 24 and 42 weeks, with both gestational age and birthweight available, were included. A measure of fetal growth was used rather than actual birthweight because birthweight and gestational age are not independent. There was simple analysis of the non-linearity of effects of fetal growth and gestation. All adjustments to weight data were made using Scottish data, ${ }^{10}$ as before. Although birthweights in Scotland are slightly higher than those in England, ${ }^{11}$ it is likely that this difference is true of twins and singletons.

Rates of cerebral palsy and population attributable risk per cent (PAR\%) have been calculated for 1980-86 to allow comparison with previously published work. ${ }^{4-5}$

Data were stored on SPSS/PC. Analysis of rates with exact binominal confidence intervals (CI) and relative risk with Taylor series CI was performed on EPIINFO6 ${ }^{12}$ and logistic regression analysis was performed using Stata (release 3.1, version 6).

\section{Results}

Twenty nine twins with cerebral palsy born between 1980 and 1986 were linked with regional data. Rates for cerebral palsy for twin cases for these years per 1000 survivors at 1 year were 6.3 (95\% CI:4.2, 9.0) and $1.2(95 \%$ $\mathrm{CI}: 1.0,1.3)$ for singletons, giving an increased 
Table 2 Data from NETRHA computed child health records 1985-1986 births

\begin{tabular}{|c|c|c|}
\hline Category & Singletons & Twins \\
\hline Numbers of total live births & 102059 & 2367 \\
\hline Total maternities with at least one live birth & 102059 & 1258 \\
\hline Total maternities with at least one survivor at 1 year & 101271 & 1236 \\
\hline Infant deaths & 788 & 78 \\
\hline Maternities affected by infant death & 788 & 60 \\
\hline Cerebral palsy cases & 104 & 17 \\
\hline Infant deaths per 1000 live births $(95 \% \mathrm{CI})$ & $7.7(7.2$ to 8.3$)$ & $32.9(26.1$ to 40.9$)$ \\
\hline Infant deaths per 1000 maternities ( $95 \% \mathrm{CI})$ & $7.7(7.2$ to 8.3$)$ & $47.7(36.6$ to 61.0$)$ \\
\hline Cerebral palsy per 10001 year survivors $(95 \% \mathrm{CI})$ & $1.0(0.8$ to 1.2$)$ & $7.4(4.3$ to 11.9$)$ \\
\hline Cerebral palsy per 1000 maternities $^{\star \star}(95 \% \mathrm{CI})$ & $1.0(0.8$ to 1.2$)$ & $11.3(6.2$ to 18.9$) \dagger$ \\
\hline $\begin{array}{l}\text { Cerebral palsy or infant death per } 1000 \text { live births } \\
(95 \% \mathrm{CI})\end{array}$ & $8.7(8.2$ to 9.3$)$ & $40.1(32.6$ to 48.8$)$ \\
\hline $\begin{array}{l}\text { Cerebral palsy or infant death per } 1000 \text { maternities } \\
(95 \% \mathrm{CI})\end{array}$ & $8.7(8.2$ to 9.3$)$ & $57.2(45.0$ to 71.5$) \ddagger$ \\
\hline
\end{tabular}

* Maternities with at least one live birth.

$\star \star$ Maternities with at least one survivor at 1 year.

† Numerator adjusted for three concordant twins.

$¥$ Numerator adjusted for three pairs of concordant twins and twin maternities affected by both cerebral palsy and cotwin death. relative risk for twins for this period of 5.3 (95\% CI 3.6, 7.7). The PAR\% of cerebral palsy for twin survivors at 1 year in NETRHA for $1980-86$ was $8.5 \%$.

Births in 1985 and 1986, where the regional denominator data are complete and validated, included 104 registered singletons and 17 twins matched with their RICHS birth records. These were derived from 102059 singleton, 2367 twins, and 85 higher order live births. Three sets were concordant for cerebral palsy. The co-twins of another three pairs had either been stillborn (one case) or had died in infancy.

Rates of death in infancy, cerebral palsy for survivors to 1 year, and "cerebral palsy or death in infancy," for 1985 and 1986, are shown in table 2 for singleton and twin births and maternities. Cerebral palsy rates from these years are statistically similar to $1980-86$ rates.
The denominator data included 16 twin pairs known to have one surviving twin at 1 year where the other had been stillborn. The rate for cerebral palsy per 1000 of these maternities was 62.5 (95\% CI 15.8, 302.3). In 38 denominator pairs one twin had been an infant death and one survived to 1 year. The rate for cerebral palsy per 1000 of these maternities was 52.6 (95\% CI 6.4, 177.5). This compares with a rate per 1000 maternities of $11.8(95 \%$ CI $6.5,19.8$ ), if both twins survived to 1 year.

Table 3 shows rates of infant death and cerebral palsy for conventional birthweight categories for both singletons and twins, and for birthweight categories for twins adjusted for the different distribution of "normal" twin weights. In table 4 rates for different gestational age groups have been calculated for maternities.

In the conventional birthweight groups the relative risk of cerebral palsy for twins compared with singletons was significantly increased for twins weighing $2500 \mathrm{~g}$ or more (relative risk $4.5 ; 95 \% \mathrm{CI} 1.4,14.4$ ). The relative risks in the lower conventional groups were raised, but not significantly. The relative risk was also raised where the gestational age was greater than or equal to 37 weeks (relative risk $6.3 ; 95 \%$ CI 2.0, 20.1).

In the adjusted birthweight groups twins weighing less than $900 \mathrm{~g}$ had a relative risk of cerebral palsy of 4.8 (95\% CI 1.4, 16.2) and between 900 and $1399 \mathrm{~g}$, one of 3.1 (95\%CI $1.1,9.1)$. The increased rate of cerebral palsy for higher birthweight twins compared with singletons is no longer significant when adjusted birthweight categories are used.

Logistic regression analysis showed that lower fetal growth, lower gestational age, and

Table 3 Distribution and rates of cerebral palsy (CP) and infant death (ID) for twin and singleton births in 1985 and 1986, for birthweight categories

\begin{tabular}{|c|c|c|c|c|c|c|c|}
\hline Birthweight categories & $\begin{array}{l}C P / 1000 \\
\text { survivors at } 1 \\
\text { year }(95 \% \text { CI) }\end{array}$ & $\begin{array}{l}\text { ID/1000 live } \\
\text { births ( } 95 \% \text { CI) }\end{array}$ & $\begin{array}{l}C P \text { or } I D / 1000 \\
\text { live births }(95 \% \\
C I)\end{array}$ & $C P$ & $\begin{array}{l}\text { Infant } \\
\text { deaths }\end{array}$ & $\begin{array}{l}\text { Live } \\
\text { births }\end{array}$ & $\begin{array}{l}\text { Survivors at } \\
1 \text { year of age }\end{array}$ \\
\hline \multicolumn{8}{|l|}{ Extremely low birthweight: } \\
\hline Twins $<900 \mathrm{~g}$ & $200(57$ to 437$)$ & $\begin{array}{l}574 \text { (422 to } \\
717)\end{array}$ & $\begin{array}{l}660 \text { (507 to } \\
791)\end{array}$ & 4 & 27 & 47 & 20 \\
\hline Singletons $<1000 \mathrm{~g}$ & $42(14$ to 95$)$ & $\begin{array}{l}528 \text { (464 to } \\
591)\end{array}$ & $\begin{array}{l}548 \text { (484 to } \\
610)\end{array}$ & 5 & 133 & 252 & 119 \\
\hline Twins $<1000 \mathrm{~g}^{\star}$ & 138 (39 to 317$)$ & $\begin{array}{l}540 \text { (409 to } \\
666)\end{array}$ & $\begin{array}{l}603 \text { (472 to } \\
724)\end{array}$ & 4 & 34 & 63 & 29 \\
\hline \multicolumn{8}{|l|}{ Very low birthweight: } \\
\hline Twins 900 to $1399 \mathrm{~g}$ & $62(20$ to 138$)$ & $\begin{array}{l}198 \text { ( } 125 \text { to } \\
289 \text { ) }\end{array}$ & $\begin{array}{l}248 \text { ( } 167 \text { to } \\
343)\end{array}$ & 5 & 20 & 101 & 81 \\
\hline Singletons 1000 to $1499 \mathrm{~g}$ & 20 (9 to 37$)$ & $\begin{array}{l}137 \text { (109 to } \\
170)\end{array}$ & $\begin{array}{l}154 \text { ( } 125 \text { to } \\
188)\end{array}$ & 9 & 73 & 531 & 458 \\
\hline Twins 1000 to $1499 \mathrm{~g}^{\star}$ & $51(17$ to 115$)$ & $\begin{array}{l}155 \text { ( } 95 \text { to } \\
234)\end{array}$ & $\begin{array}{l}198 \text { (130 to } \\
283)\end{array}$ & 5 & 18 & 116 & 98 \\
\hline \multicolumn{8}{|l|}{ Low birthweight: } \\
\hline Twins 1400 to $2199 \mathrm{~g}$ & 9 (3 to 22$)$ & $24(13$ to 40$)$ & 33 (20 to 52 ) & 5 & 13 & 547 & 534 \\
\hline Singletons 1500 to $2499 \mathrm{~g}$ & $6(4$ to 9$)$ & 30 (26 to 35$)$ & 36 (31 to 42$)$ & 33 & 159 & 5286 & 5127 \\
\hline Twins 1500 to $2499 \mathrm{~g}^{\star}$ & $5(2$ to 12$)$ & $16(9$ to 26$)$ & 21 (13 to 32$)$ & 5 & 16 & 999 & 983 \\
\hline \multicolumn{8}{|l|}{ Normal birthweight: } \\
\hline Twins $\geq 2200 \mathrm{~g}$ & $1.9(0.4$ to 5.6$)$ & 10 (6 to 16$)$ & $12(7$ to 19$)$ & 3 & 16 & 1586 & 1570 \\
\hline Singletons $\geq 2500 \mathrm{~g}$ & $0.6(0.5$ to 0.8$)$ & $\begin{array}{l}4.4 \text { (4.0 to } \\
4.8)\end{array}$ & 5.0 (4.5 to 5.5$)$ & 57 & 413 & 94245 & 93832 \\
\hline Twins $\geq 2500 \mathrm{~g}^{\star}$ & $3(1$ to 8$)$ & 7 (3 to 14$)$ & 10 (5 to 18$)$ & 3 & 8 & 1103 & 1095 \\
\hline \multicolumn{8}{|l|}{ Birthweight unknown: } \\
\hline Twins & 0 (0 to 43$)$ & 23 (3 to 81$)$ & 23 (3 to 81$)$ & 0 & 2 & 86 & 84 \\
\hline Singletons & 0 (0 to 2$)$ & $6(3$ to 11$)$ & $6(3$ to 11$)$ & 0 & 10 & 1745 & 1735 \\
\hline \multicolumn{8}{|l|}{ Total: } \\
\hline Twins & 7 (4 to 12$)$ & $33(26$ to 41$)$ & 40 (33 to 49 ) & 17 & 78 & 2367 & 2289 \\
\hline Singletons & $1.0(0.8$ to 1.2$)$ & $\begin{array}{l}7.7(7.2 \text { to } \\
8.3)\end{array}$ & 8.7 (8.2 to 9.3 ) & 104 & 788 & 102059 & 101271 \\
\hline
\end{tabular}


Table 4 Distribution and rates of cerebral palsy (CP) and infant death (ID) for twin and singleton maternities in 1985 and 1986, for gestational age

\begin{tabular}{|c|c|c|c|c|c|c|c|}
\hline $\begin{array}{l}\text { Gestational age } \\
\text { categories }\end{array}$ & $\begin{array}{l}C P / 1000^{\star *} \\
(95 \% C I)\end{array}$ & $\begin{array}{l}I D / 1000 *(95 \% \\
C I)\end{array}$ & $\begin{array}{l}\text { †CP or ID/1000* } \\
(95 \% \text { CI })\end{array}$ & $\neq C P$ & $\begin{array}{l}\text { Infant } \\
\text { deathstt }\end{array}$ & $\begin{array}{l}\text { Live } \\
\text { births* }\end{array}$ & $\begin{array}{l}\text { Survivors age } \\
1 \text { year }^{\star \star}\end{array}$ \\
\hline \multicolumn{8}{|l|}{$\leq 28$ weeks } \\
\hline Twins & $63(8$ to 208$)$ & $\begin{array}{l}549 \text { (403 to } \\
689)\end{array}$ & 588 (442 to 724$)$ & 2 & 28 & 32 & 51 \\
\hline Singletons & $32(13$ to 64$)$ & $\begin{array}{l}410 \text { (359 to } \\
461)\end{array}$ & 428 (378 to 480$)$ & 7 & 154 & 222 & 376 \\
\hline \multicolumn{8}{|l|}{29 to 32 weeks } \\
\hline Twins & 51 (17 to 114$)$ & 89 (42 to 162 ) & 129 (70 to 210$)$ & 5 & 9 & 99 & 101 \\
\hline Singletons & $28(18$ to 42$)$ & $88(70$ to 109$)$ & 113 (93 to 136$)$ & 22 & 76 & 790 & 866 \\
\hline \multicolumn{8}{|l|}{33 to 36 weeks } \\
\hline Twins & 9 (2 to 27$)$ & 25 (11 to 48$)$ & 34 (17 to 60$)$ & 3 & 8 & 326 & 326 \\
\hline Singletons & $3(2$ to 5$)$ & $25(21$ to 31$)$ & 28 (23 to 34$)$ & 12 & 111 & 4252 & 4363 \\
\hline \multicolumn{8}{|l|}{$\geq 37$ weeks } \\
\hline Twins & $4(0.9$ to 12$)$ & 20 (11 to 33$)$ & $24(14$ to 38$)$ & 3 & 14 & 704 & 704 \\
\hline Singletons & $0.7(0.5$ to 0.9$)$ & $4.7(4.3$ to 5.1$)$ & $5.4(4.9$ to 5.8$)$ & 63 & 441 & 93636 & 94077 \\
\hline \multicolumn{8}{|l|}{ Unknown } \\
\hline Twins & $13(0.3$ to 72$)$ & $13(0.3$ to 71$)$ & $13(0.3$ to 71$)$ & 1 & 1 & 75 & 76 \\
\hline Singletons & 0 (0 to 1.6$)$ & $2.5(0.9$ to 5.5$)$ & $2.5(0.9$ to 5.5$)$ & 0 & 6 & 2371 & 2377 \\
\hline \multicolumn{8}{|l|}{ Total } \\
\hline Twins & 11 (6 to 19$)$ & 48 (37 to 61$)$ & 57 (45 to 72$)$ & 14 & 60 & 1236 & 1258 \\
\hline Singletons & $1.0(0.8$ to 1.2$)$ & $7.7(7.2$ to 8.3$)$ & 8.7 (8.2 to 9.3$)$ & 104 & 788 & 101271 & 102059 \\
\hline
\end{tabular}

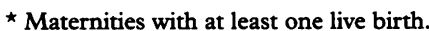

$\star \star$ Maternities with at least one survivor.

† Numerator adjusted for twin maternities affected by both cerebral palsy and cotwin death.

tt Maternities affected by infant deaths.

$\ddagger$ Maternities affected by cerebral palsy.

being a twin all independently increased the risk of cerebral palsy. The correlations between cerebral palsy and gestational age and fetal growth were not, however, best described as linear.

Gestational age had the strongest influence on outcome, with each additional week in gestation decreasing the risk of cerebral palsy by a factor of $0.76(95 \%$ CI $0.69,0.82)$. The risk of cerebral palsy for children born before 33 weeks of gestation was additionally increased by a factor of 2.8 (95\% CI 1.1, 6.9). However, small numbers preclude establishing whether the effect of gestational age on risk of cerebral palsy is due to steepening of a linear relation at very low gestational age or is indeed a step effect.

Children with low fetal growth were at a fourfold increased risk of cerebral palsy (odds ratio $4.0 ; 95 \%$ CI 2.3, 6.8). For children who were not of low fetal growth, the risk of cerebral palsy was decreased by a factor of 0.82 for each increase in fetal growth of one standard deviation. This protective effect was not, however, significant $(P=0.10)$.

Being a twin nearly doubled the risk of cerebral palsy (odds ratio $1.9 ; 95 \%$ CI 1.1 , 3.4). The risk (odds ratio) of cerebral palsy for

Table 5 Numbers (\%) of twins and singletons for different distributions and neurological type of cerebral palsy maternities in 1985 and 1986

\begin{tabular}{|c|c|c|}
\hline & $\begin{array}{l}\text { Singletons (\%) } \\
(95 \% \text { CI })\end{array}$ & Twins (\%) $(95 \%$ CI) \\
\hline \multicolumn{3}{|l|}{ Distribution } \\
\hline Hemiplegia & $18(17.3)(10.6$ to 26.0$)$ & $5(29.4)(10.3$ to 56.0$)$ \\
\hline Asymmetric quadriplegia & $13(12.5)(6.8$ to 20.4$)$ & $4(23.5)(6.8$ to 49.9$)$ \\
\hline Diplegia & $19(18.3)(11.4$ to 27.1$)$ & $2(11.8)(1.5$ to 36.4$)$ \\
\hline Quadriplegia & 33 (31.7) (22.9 to 41.6$)$ & $5(29.4)(10.3$ to 56.0$)$ \\
\hline Monoplegia & $4(3.8)(1.1$ to 9.6$)$ & $0(0)(0.0$ to 19.5$)$ \\
\hline Not available & $17(16.3)(9.8$ to 24.9$)$ & $1(5.9)(0.1$ to 28.7$)$ \\
\hline \multicolumn{3}{|r|}{ (80, } \\
\hline $\begin{array}{l}\text { Athetoid or ataxia or hypotonia or } \\
\text { dystonia alone }\end{array}$ & 8 (7.7) (3.4 to 14.6 ) & $1(5.9)(0.1$ to 28.7$)$ \\
\hline Mixed but no spasticity & $4(3.8)(1.1$ to 9.6$)$ & $1(5.9)(0.1$ to 28.7$)$ \\
\hline Mixed with spasticity & $22(21.2)$ (13.8 to 30.3$)$ & $3(17.6)(3.8$ to 43.4$)$ \\
\hline Spasticity alone & $53(51.0)(41.0$ to 61.0$)$ & $\begin{array}{l}11(64.7) \text { (38.3 to } \\
85.8)\end{array}$ \\
\hline Not available & 17 (16.3) (9.8 to 24.9$)$ & $1(5.9)(0.1$ to 28.7$)$ \\
\hline
\end{tabular}

twins compared with singletons was 5.6 (95\% CI 1.2, 26.2) times greater in babies of low fetal growth, compared with 1.7 (95\% CI 0.93, 3.1) times greater for babies who were not of low fetal growth. However, these two effects were not significantly different $(P=0.15)$ from the combined odds ratio of 1.9 .

Table 5 shows cerebral palsy type and distribution for singletons and twins. Fifty three per cent $(95 \%$ CI $27.8,77.0)$ of twins and $29.8 \%$ $(95 \%$ CI $21.2,39.6)$ of singletons had asymmetric cerebral palsy, either hemiplegia or asymmetric quadriplegia. Despite an increased proportion of preterm twins a smaller per cent had diplegia. Three out of 17 twins $(17.6 \%$; $95 \%$ CI $3.8,43.4$ ) were reported to have porencephalic cysts, compared with four out of 104 singletons $(3.8 \%$; 95\% CI 1.1, 9.6).

Neither sex distribution nor order of birth affected the risk of cerebral palsy.

\section{Discussion}

The rate of cerebral palsy for NETRHA for all years and 1985 and 1986 is lower for singletons than reported in Western Australia, ${ }^{4}$ but similar for both twins and singletons to that reported in California. ${ }^{5}$ This paper has largely been confined to the years where both numerator and denominator are of good quality.

Findings in NETRHA confirm the significant increase in the risk of cerebral palsy in twins weighing $2500 \mathrm{~g}$ or more. ${ }^{4-5}$ They differ from those previously reported by showing an increased risk of cerebral palsy in twins for two of the three low birthweight categories, albeit not at a level of significance.

The need to make adjustments in line with known birthweight distributions of different populations being compared has been suggested for evaluating perinatal mortality of white and black populations in the USA, ${ }^{13}$ and in twins and singletons. ${ }^{14}$ Analysis which compares rates of cerebral palsy for these adjusted birthweight groups with the equivalent conven- 
tional categories for singletons shows an increased risk of cerebral palsy in all weight categories that is significant in two of the three low birthweight categories.

Few other reports have looked at risk of twins for cerebral palsy by their gestational age. When the risk of having one or more twins affected by cerebral palsy is compared with the risk in singleton maternities, an increased risk is shown in all gestational age groups. The relative risk is greatest, and significant, for twins born at or after 37 weeks of gestation, although their absolute rate is lower than that for more immature twins.

Multiple logistic regression analysis confirmed the importance of twinning as a risk factor for cerebral palsy, regardless of weight and gestational age. It has also confirmed that there are independent effects of gestational age and fetal growth. Statistically, however, these three risk factors still only account for a minority of all cases of cerebral palsy seen.

The equal proportion of first and second twins with cerebral palsy in North East Thames is insufficient to discount a real difference in birth order of twins with cerebral palsy if a larger group of twins were studied. If only twins not otherwise at increased risk of cerebral palsy, namely those who have a normal surviving co-twin aged 1 or more, are considered and published data from California ${ }^{5}$ and Western Australia ${ }^{4}$ are added to our findings, 27 out of 39 cases $(69 \%$; 95\% CI 52, 83) with cerebral palsy were second born.

It has been suggested that twinning confers an increased risk of cerebral palsy because of increased vulnerability of blood flow in utero. ${ }^{15}$ A recent study of hemiplegia in twins found that this condition was notable for the lack of concordance in twin pairs. ${ }^{16}$ The excess of cases of asymmetric cerebral palsy in twins in this sample is of interest but numbers are too small to permit meaningful statistical comparisons.

The population attributable risk per cent quantifies the burden of cerebral palsy due to twinning in NETRHA. RICHS data for 1990 show an increased proportion of twin survivors compared with 1980-86 data. If the risk of cerebral palsy in twins and singletons is the same in 1990 as calculated for 1980-86, the increased proportion of twins would have increased the PAR\% from $8.5 \%$ to $9.1 \%$.

The implications of an increased risk of cerebral palsy or infant death for twins is undeniably important for counselling parents facing the choice of a multiple or singleton pregnancy. The implications for the population of a substantial, and potentially increasing, proportion of cerebral palsy cases from multiple births is important for prevention and service planning. Clear hypotheses about the likely aetiologies of the increased risk of cerebral palsy for twins compared with singletons are hard to disentangle. This could be because the aetiology is multifactorial and confounding factors and sample size are preventing the emergence of clearer patterns. A multicentre study, which has combined data from cerebral palsy registers in Britain, the USA, and Australia, is in progress and may clarify these issues.

The study was supported by SCOPE. It was initiated and overseen by Dr Pamela Evans and continued by Dr Arbi Mlika, both of whose help we gratefully acknowledge. We also thank all the paediatricians and other collaborators who ascertained cases paediatricians and other collaborators who ascertained cases (old) NE Thames RHA Districts for providing data, and the regional headquarters (HBO) for their help facilitating data provision.

1 Alberman E. Cerebral palsy in twins. Guys' Hospital Reports 1964; 113:285-95.

2 McCarthy BJ, Sachs BP, Layde PM, Burton A, Terry JS, Rochat R. The epidemiology of neonatal death in twins. Am $\mathcal{F}$ Obstet Gynecol 1981; 141:252-61.

3 Ghai V, Vidyasagar D. Morbidity and mortality factors in twins. Clin Perinatol 1988; 15:123-57.

4 Petterson B, Nelson KB, Watson L, Stanley F. Twins, triplets, and cerebral palsy in births in Western Australia in the 1980s. BMF 1993; 307:1239-43.

5 Grether JK, Nelson KB, Cummins SK. Twinning and cerebral palsy: experience in four northern California counties, births 1983 through 1985 . Pediatrics 1993 92:854-8.

6 Levene MI, Wild J, Steer P. Higher multiple births and the modern management of infertility in Britain. Br $₹$ Obstet modern management of in

7 OPCS. The health of our children. Decennial Supplement, Series DF No. 11, OPCS. London: HMSO, 1995: 71.

8 Mlika A, Alberman E, Evans P. Use of regional child health records to study risk factors for cerebral palsy in multiple births. F Epidemiol Comm Health 1993; 47:420-1.

9 Evans PM, Alberman E. Recording motor defects in children with cerebral palsy. Dev Med Child Neurol 1985 27:404-6.

10 Information and Statistics Division, Scottish Health Service, Common Services Agency. Scotland. Birthweight, head circumference and length for gestational age. Edinburgh: ISD Publication.

11 Buckler JMH, Green M. Birth weight and head circumference standards for English twins. Arch Dis Child 1994; 71:516-21.

12 Dean AG, Dean JA,Coulombier D, Brendal KA, Smith DC Burton AH, et al. Epi Info, Version 6: $A$ word processing, database, and statistics program for epidemiology on microcom puters. Atlanta, Georgia: Centers for Disease Control and Prevention, 1994

13 Wilcox A, Russell I. Why small black infants have a lower mortality rate than small white infants: The case for population specific standards for birth weight. $\mathcal{f}$ Pediatr 1990 116:7-10.

14 Buekens $\mathrm{P}$, Wilcox $\mathrm{A}$. Why do small twins have a lower mortality than small singletons? Am 7 Obstet Gynecol 1993, 168:937-41.

15 Scheller JM, Nelson KB. Twinning and neurologic morbidity. $A m \mathcal{F}$ Dis Child 1992;146:1110-13.

16 Goodman R, Alberman E. A twin study of congential hemiplegia. Dev Med Child Neurol 1996; 38:3-12. 